\title{
Resource integration
}

\section{Michael Kleinaltenkamp}

Marketing Department, Freie Universität Berlin, Germany

\section{Roderick J. Brodie}

Marketing Department, University of Auckland Business School, New Zealand

\section{Pennie Frow}

Discipline of Marketing, University of Sydney, Australia

\section{Tim Hughes}

Bristol Business School, University of the West of England, UK

\section{Linda D. Peters}

Nottingham University Business School, UK

\section{Herbert Woratschek}

Department of Services Management, Universität Bayreuth, Germany

Core to developing a general theory of markets, service-dominant (S-D) logic suggests that service is the fundamental basis of exchange (Vargo and Lusch, 2004). In turn, 'Service provision implies the ongoing combination of resources, through integration, and their application' (Vargo and Lusch, 2010: 4); hence the central role of resource integration as the means through which resource integrators (actors) co-create phenomenologically determined value.

We identify five themes relevant to gaining a clearer understanding of the role of social and economic factors in resource integration. The themes and the broad relationships between them are conceptualized in Figure 1. Here we identify actors who possess appropriate resources which they are allowed and able to share, co-creating value using collaborative and integrative processes. Their evaluation of each experience occurs within the context of each specific engagement and provides continuous input into future collaborations. The resulting value may impact both the ability of actors to exercise agency and the processes involved in integrating resources.

\section{Resource integrators}

The modified foundational premise (FP9): 'All social and economic actors are resource integrators' (Vargo and Lusch, 2008) recognizes the role of multiple actors in networks. It follows that there is a need to better understand 'the commonalities of the activities of actors that constitute the

\section{Corresponding author:}

Michael Kleinaltenkamp, Marketing Department, School of Business \& Economics, Freie Universität Berlin, Otto-vonSimson-Str. 19, D-14195 Berlin, Germany

Email: michael.kleinaltenkamp@fu-berlin.de 


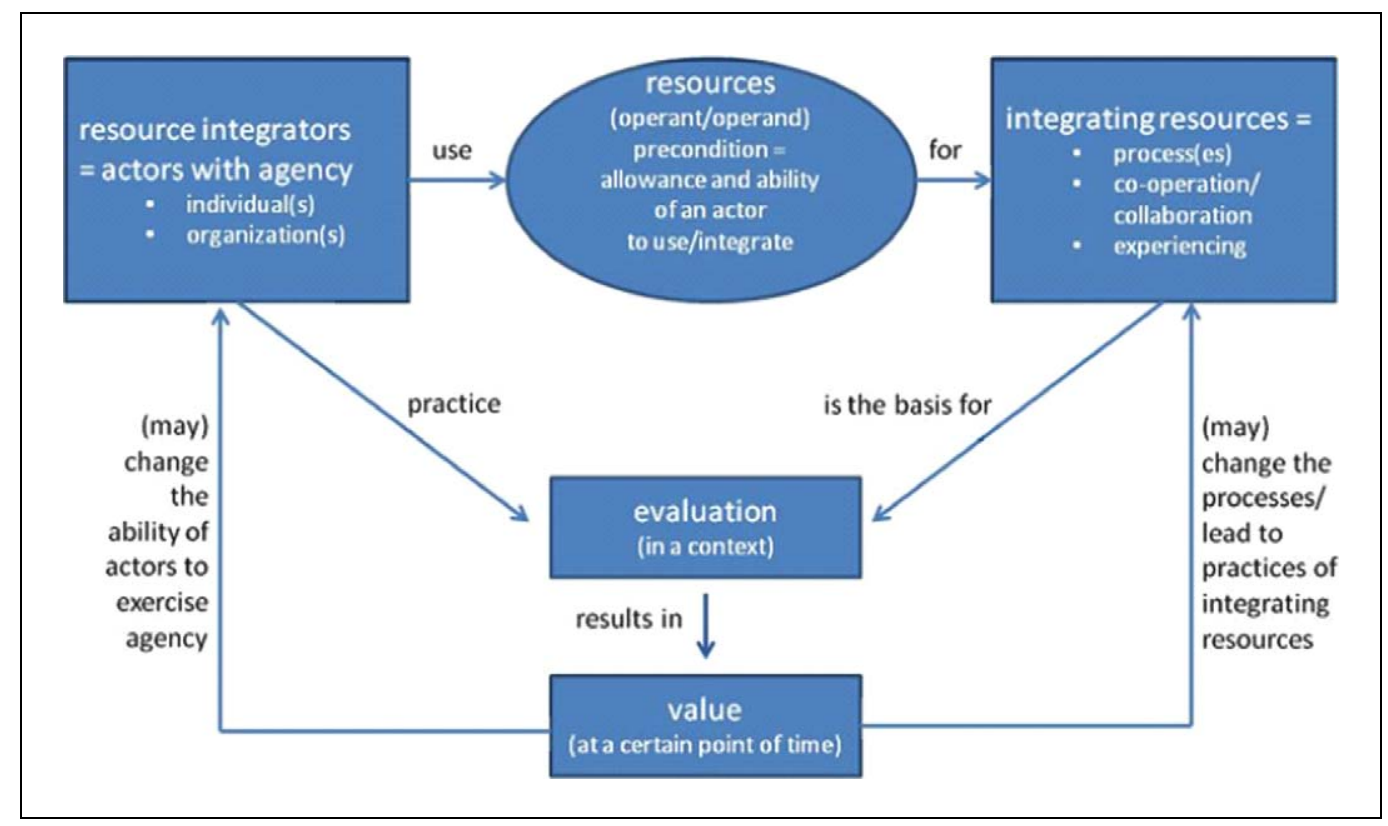

Figure I. Resource integration framework

market(s)' (Vargo and Lusch, 2010: 6) and the nature of networks that are linked together by 'the trinity of competences, relationships and information' (Lusch et al., 2010: 21). The perspective provided by structuration theory (Giddens, 1984) and subsequent work in sociology may be helpful here in analyzing resource integrators' practices and the social structures in which they take place. A key question is the essentiality of human agency - seen as the ability of self-reflexive actors to act with choice (Archer, 2000) - and specifically whether technology can itself be a resource integrator and can forge relationships between other things embedded with knowledge capabilities. This difficulty in conceptualizing the nature of the role of technology is a recurring theme in considering several aspects of resource integration.

\section{Resources}

Resource integrators utilize resources of which 'Operant resources are the fundamental source of competitor advantage' (FP4, Vargo and Lusch, 2008). S-D logic with its emphasis on the resources supplied by all actors (customer, supplier and other stakeholders within a network of relationships) provides an interesting contrast with the established resource-based view (RBV), focusing only on the resources of the supplying organization and the way they are deployed in creating a sustainable competitive advantage (Prahalad and Hamel, 1990). The emphasis in S-D logic on all those in the network of actors raises new questions on the nature of resources and the need to understand how resources are mobilized and utilized.

There are fundamental preconditions for resource integration, including actors possessing the ability and allowance to use or integrate a resource. These preconditions enable actors to utilize a resource and to make an exchange of 'service for service' possible (Haase and Kleinaltenkamp, 2011). Despite the useful distinction between operant and operand resources (Vargo and Lusch, 
2004), these concepts require further clarification. As SD-logic views resources as a function of human appraisal, this dual categorization can become confusing. In particular, the question remains as to whether technology can provide an operant resource in certain circumstances (e.g. machine to machine communication and learning) or whether the application of an operant resource requires human agency.

\section{Integrating resources}

Integration requires process(es) and forms of collaboration. There is much to learn about the practices of integrating resources and how to design and configure the integration process. Two theories, effectuation theory (Read et al., 2009) and configuration theory (Miller, 1987), offer some insights into this process. Effectuation theory questions the predictive rationale for organizational behavior, suggesting collaboration occurs through commitments between networked actors. Configuration theory seeks to explain how organizations configure their resources, responding to the environment through the agency of their people. Technology is often central to the integration process, and the role of people interacting with technology is a key issue within service systems research (Maglio and Spohrer, 2008). However, we need to look further than the interaction to fully understand the co-creation of value. It is the human and social experience resulting from the interaction with engagement platforms that is crucial (Ramaswamy, 2010). Therefore, we need to understand more about the experiences of the actors within the integrating process (Lemke at al., 2010).

Also important is the mechanism of relational governance that guides the collaboration involved in resource integration (Heide, 1994). As the collaborations are usually voluntary, the actors need to recognize the benefit from participation. If the benefit is not evident to the actors, then collaborative activity is unlikely.

\section{Evaluation}

The phenomenological nature of value means that research methods include exploring the evaluation of the actors involved. Vargo and Lusch (2008) emphasize that value is determined uniquely and phenomenologically by the beneficiary (FP10). This idea needs more investigation. There may be a number of beneficiaries and the determination of value may be complex. Recent findings highlight that value is not only the function of discrete events, but also relates to multiple episodes in an overall relationship. Thus, resource integration may take place episodically and the value appraisal of the resource integrators has an impact on relationship outcomes as well as on the actors' future behavior and future practices involved in integrating resources (Ford, 2010; Lemke et al., 2010).

\section{Value}

The co-creation of value is portrayed in S-D logic as the outcome of resource integration. The supplying organization can only make value propositions (FP7, Vargo and Lusch, 2008) and cocreated value is phenomenologically experienced when two or more actors integrate their resources. But there is little consensus about the nature, meaning and measurement of value in the general literature (Sánchez-Fernández and Iniesta-Bonillo, 2007). To what extend is it possible to have a common conceptualization of a construct that is complex and subjective? Deconstructing value into various forms of value co-creating activity, from co-conceiving ideas, through 
co-production to co-disposal, provides some insights into value collaborations. Yet much work remains to unravel the nature of this intriguing construct.

From our brief discussion of these five themes and their relevance in understanding the role of social and economic factors as resource integrators in the context of S-D Logic, we identify ten key research challenges for investigation.

Theme I: Resource integrators. A key task is defining resource integrators, especially in the context of technology:

- What is the role of technology in resource integration - can technology be a resource integrator and/or a resource?

- What do we know about the motivation and behavior of resource integrators and what are the implications for theory and practice?

Theme 2: Resources. Research priorities include clarifying the nature of operant and operand resources and the implications for their subjective, dual classification:

- What is the nature of a resource in the context of S-D logic and what is its relationship with actors?

- Can technology provide an operant resource or does the application of an operant resource require human agency?

Theme 3: Integrating resources. This theme offers challenges in understanding the nature of interactivity and reciprocity of value co-creation:

- What is the role of practices in resource integration?

- How can business model design and configuration processes assist the resource integration process?

Theme 4: Value. Although S-D logic offers a clearly articulated perspective of value, many questions remain, including:

- What is the role of value propositions in resource integration within a service system?

- Is value the outcome of resource integration or intrinsic within the interaction experience?

Theme 5: Evaluation. Understanding the evaluation process of networked resource integrators poses interesting challenges, including:

- What tools assist in measuring value within a service system? What is the impact on co-created value of the evaluation by each actor within a service system?

- What methods allow researchers to understand most clearly the nature and evaluation of phenomenological value? 


\section{References}

Archer, M. (2000) Being Human: The Problem of Agency. Cambridge: Cambridge University Press.

Ford, D. (2010) 'IMP and Service-dominant Logic: Divergence, Convergence and Development', Industrial Marketing Management doi:10.1016/j.indmarman.2010.06.035.

Giddens, A. (1984) The Constitution of Society. Berkeley, CA: University of California Press .

Haase, M. and Kleinaltenkamp, M. (2011) 'Property Rights Design and Market Process: Implications for Market Theory, Marketing Theory and S-D Logic', Journal of Macromarketing 31(2): 148-59.

Heide, J.B. (1994) 'Interorganizational Governance in Marketing Channels', Journal of Marketing 58(January): 71-85.

Lemke, F., Clark, M. and Wilson, H. (2010) 'Customer Experience Quality: An Exploration in Business and Consumer Contexts Using Repertory Grid Technique', Journal of the Academy of Marketing Science 39(2011): 846-69.

Lusch, R.F., Vargo, S.L. and Tanniru, M. (2010) 'Service, Value Networks and Learning', Journal of the Academy of Marketing Science 38: 19-31.

Maglio, P.P. and Spohrer, J. (2008) 'Fundamentals of Service Science', Journal of the Academy of Marketing Science 36: 18-20.

Miller, D. (1987) 'The Genesis of Configuration', Academy of Management Review 12(4): 670-87.

Prahalad, C.K. and Hamel, G. (1990) 'The Core Competence of the Corporation', Harvard Business Review May-June: 79-91.

Ramaswamy, V. (2010) 'It's about Human Experiences ... and beyond, to Co-creation', Industrial Marketing Management doi:10.1016/j.indmarman.2010.06.030.

Read, S., Dew, N., Sarasvathy, S., Song, M. and Wiltbank, R. (2009) 'Marketing under Uncertainty: The Logic of an Effectual Approach', Journal of Marketing 73(May): 1-18.

Sánchez-Fernández, R. and Iniesta-Bonillo, M.A. (2007) 'The Concept of Perceived Value: A Systematic Review of the Research', Marketing Theory 7(4): 427-51.

Vargo, S.L. and Lusch, R.F. (2004) 'Evolving to a New Dominant Logic for Marketing', Journal of Marketing 68(1): $1-17$.

Vargo, S.L. and Lusch, R.F. (2008) 'Service-dominant Logic: Continuing the Evolution', Journal of the Academy of Marketing Science 36: 1-10.

Vargo, S. and Lusch, R.F. (2010) 'It's all B2B ... and beyond: Toward a Systems Perspective of the Market', Industrial Marketing Management 40(2011): 181-7. 